\title{
Adaptive dosing and platinum-DNA adduct formation in children receiving high-dose carboplatin for the treatment of solid tumours
}

\author{
GJ Veal', J Errington', MJ Tilby', ADJ Pearson², ABM Foot ${ }^{3}$, H McDowell $^{4}$, C Ellershaw ${ }^{5}$, B Pizer ${ }^{4}$, GM Nowell, $^{6}$, \\ DG Pearson ${ }^{6}$ and AV Boddy*,1, on behalf of the UKCCSG Pharmacology Working Group
}

'Northem Institute for Cancer Research, University of Newcastle upon Tyne, Newcastle upon Tyne, NE2 4HH, UK: ${ }^{2}$ Royal Marsden Hospital, Surrey, SM2 5PT, UK; ${ }^{3}$ Bristol Royal Hospital for Children, Bristol, BS2 8BJ, UK; ${ }^{4}$ Alder Hey Children's Hospital, Liverpool, LI 2 2AP, UK; ${ }^{5}$ United Kingdom Children's Cancer Study Group, Leicester, LEI 6TP, UK; ${ }^{6}$ Department of Earth Sciences, Durham University, Durham, DHI 3LE, UK

\begin{abstract}
A pharmacokinetic-pharmacodynamic study was carried out to investigate the feasibility and potential importance of therapeutic monitoring following high-dose carboplatin treatment in children. High-dose carboplatin was administered over 3 or 5 days, with the initial dose based on renal function, to achieve target area under the plasma concentration-time curve (AUC) values of $2 \mathrm{I}$ or $20 \mathrm{mg} \mathrm{ml}^{-1}$.min, respectively. Dose adjustment was carried out based on observed individual daily AUC values, to obtain the defined target exposures. Platinum-DNA adduct levels were determined in peripheral blood leucocytes and toxicity data were obtained. Twenty-eight children were studied. Based on observed AUC values, carboplatin dose adjustment was performed in $75 \%$ (2I out of 28) patients. Therapeutic monitoring resulted in the achievement of carboplatin exposures within $80-126 \%$ of target AUC values, as compared to estimated exposures of $65-213 \%$ of target values without dose adjustment. The carboplatin AUC predicted with no dose modification was positively correlated with pretreatment glomerular filtration rate (GFR) values. Higher GFR values were observed in those patients who would have experienced AUC values $>25 \%$ above the target AUC than those patients attaining AUC values $>25 \%$ below the target AUC, following renal function-based dosing. Platinum-DNA adduct levels correlated with observed AUC values on day I of carboplatin and increased over a 5-day course of treatment. Real-time monitoring of carboplatin pharmacokinetics with adaptive dosing is both feasible and necessary for the attainment of consistent AUC values in children receiving high-dose carboplatin treatment. Pharmacodynamic data suggest a strong correlation between carboplatin pharmacokinetics and the drug-target interaction.
\end{abstract}

British Journal of Cancer (2007) 96, 725-731. doi:10.1038/sj.bjc.6603607 www.bjcancer.com

Published online 13 February 2007

(c) 2007 Cancer Research UK

Keywords: carboplatin; therapeutic monitoring; clinical pharmacology; paediatrics; platinum-DNA adducts

Carboplatin is a second-generation platinum compound commonly used in paediatric oncology and currently plays a key role in the treatment of many tumours, including neuroblastoma, rhabdomyosarcoma, brain tumours and germ cell tumours (Gaynon, 1994). It is estimated that approximately one-third of children with solid tumours will receive carboplatin as part of multimodal chemotherapy at some point during their treatment. As the pharmacokinetics of carboplatin are largely determined by the renal function of the patient being treated, dosing formulae have been devised to calculate the dose of carboplatin required to achieve the desired target exposure or area under the plasma concentration - time curve (AUC) (Calvert et al, 1989; Newell et al, 1993; Ando et al, 2000). This approach has been shown to result in more consistent exposure to carboplatin than dosing based on

*Correspondence: Dr AV Boddy, Northern Institute for Cancer Research, Medical School, Framlington Place, University of Newcastle upon Tyne, Newcastle upon Tyne, NE2 4HH, UK;

E-mail: Alan.Boddy@ncl.ac.uk

Received 16 October 2006; revised 3 January 2007; accepted 7 January 2007; published online 13 February 2007 body surface area in a randomized, cross-over study in children with cancer (Thomas et al, 2000). Renal function-based carboplatin dosing has now become widely accepted, with an increasing number of paediatric clinical protocols specifying carboplatin dosed to a target AUC. The rationale for this approach is supported by the observation that carboplatin AUC is correlated more closely than drug dose with both clinical toxicity and response in adults and children (Newell et al, 1987; Jodrell et al, 1992).

Although this approach is now routinely used for carboplatin administered at conventional doses (AUC $4-7 \mathrm{mg} \mathrm{ml}^{-1}$. min), its application to high-dose carboplatin chemotherapy is less well understood. When high-dose chemotherapy is used in the treatment of poor prognosis patients, saturation of protein binding or drug metabolism may result in unpredictable pharmacokinetic variation. Our group and others have previously suggested that real-time carboplatin monitoring, involving dose modification based on pharmacokinetic variation, can result in the achievement of target exposures in individual patients following carboplatin chemotherapy (Veal et al, 1999; Chatelut et al, 2000; Rubie et al, 2003). This approach to treatment may be particularly important in a high-dose chemotherapy setting where treatment-related 
deaths are not uncommon. The current study, involving a relatively large number of patients being treated with high-dose carboplatin, was designed to determine whether adaptive dosing would allow target AUC values to be consistently achieved, while reducing the variability in plasma concentrations as compared to renal function-based dosing.

In addition to learning more about the pharmacokinetics of drugs used in the treatment of children with cancer, it is also important to consider molecular pharmacodynamic interactions. Although a number of studies have indicated relationships between platinum-DNA adduct formation in peripheral blood leucocytes and clinical response and toxicity following cisplatin treatment, there is little evidence to support the use of pharmacodynamic end points for carboplatin (Reed et al, 1990; Schellens et al, 1996; Veal et al, 2001). Whether or not this can be explained by a lack of correlation between carboplatin pharmacokinetics and pharmacodynamics is at present unclear.

The design of a United Kingdom Children's Cancer Study Group (UKCCSG) protocol for the treatment of low-risk patients with metastatic rhabdomyosarcoma and other malignant soft tissue sarcomas (MMT 98 study) provided a rare opportunity to investigate carboplatin exposure, platinum-DNA adduct formation and clinical toxicity, in a single agent high-dose paediatric setting. Additional data were also obtained from a UKCCSG study involving the treatment of recurrent central nervous (CNS) system primitive neuroectodermal tumours (Recurrent PNET study). Carboplatin was administered with target AUCs of $20 \mathrm{mg} \mathrm{ml}^{-1}$.min over 5 days or $21 \mathrm{mg} \mathrm{ml}$.min over 3 days for the treatment of soft tissue sarcoma or recurrent PNET patients respectively. Carboplatin pharmacokinetics were monitored following initial renal function-based dosing, with dose adjustments implemented based on observed AUC values. In a subset of patients, platinum-DNA adduct levels were determined in peripheral blood leucocytes.

\section{PATIENTS AND METHODS}

\section{Patient eligibility and treatment}

The study protocols were approved by the UK Northern and Yorkshire Multicentre Research Ethics Committee and participating centres obtained local ethical approval; written informed consent was required, either from patients or parents as appropriate, for all patients entered onto the study. Patients, 21 years or younger, receiving high-dose carboplatin chemotherapy as part of their standard clinical treatment, were eligible (Table 1). Patients were being treated on clinical protocols for either soft tissue sarcoma (UKCCSG MMT 98 study) or recurrent primitive neuroectodermal tumour (UKCCSG recurrent PNET study). All patients were required to have central venous access, in the form of double-lumen central venous catheters, to participate in this pharmacokinetic study.

Carboplatin was administered diluted in 5\% dextrose, as a $60 \mathrm{~min}$ intravenous infusion, as part of the standard chemotherapy regimen that each patient was currently receiving. The dose of carboplatin administered on day 1 of treatment was determined by the renal function of the patient, based on either ${ }^{51} \mathrm{Cr}$-EDTA halflife or glomerular filtration rate (GFR), using equations described previously (Newell et al, 1993). Patients being treated for soft tissue sarcoma received carboplatin dosed to a target AUC of $20 \mathrm{mg} \mathrm{ml}^{-1}$.min over a 5 -day treatment period. Before entering this high-dose consolidation phase of chemotherapy, patients were entered onto a phase II 'window study' consisting of single-agent carboplatin targeted to obtain an AUC of $10 \mathrm{mg} \mathrm{ml}^{-1}$.min on each of the two courses of treatment. Patients being treated for recurrent CNS primitive neuroectodermal tumours received carboplatin dosed to a target AUC of $21 \mathrm{mg} \mathrm{ml}^{-1}$.min over 3 days. These dosages were determined by the clinical protocols for the
Table I Patient characteristics

\begin{tabular}{lcr}
\hline Characteristic & No. of patients & $\%$ \\
\hline Age, (years) & & \\
$<5$ & 4 & 14 \\
$5-9$ & 5 & 18 \\
$10-14$ & 12 & 43 \\
$15-2 \mid$ & 7 & 25 \\
& & \\
Sex & 14 & 50 \\
Male & 14 & 50 \\
Female & & \\
& & 18 \\
Diagnosis & 5 & 43 \\
Soft tissue sarcoma (MMT 98) & 12 & 39 \\
Rhabdomyosarcoma (MMT 98) & 11 & \\
PNET & & 61 \\
& & 100 \\
Additional chemotherapy & 17 & 39 \\
Etoposide & 28 & 98 \\
Cyclophosphamide & 11 & \\
Thiotepa & & \\
\hline
\end{tabular}

PNET, primitive neuroectodermal tumour. For patients treated on the MMT 98 study, cyclophosphamide $\left(2 \mathrm{~g} \mathrm{~m}^{-2} \mathrm{day}^{-1} \times 3\right)$ was administered to patients on two courses of treatment, 6 and 2 weeks before receiving high-dose carboplatin, with etoposide $\left(800 \mathrm{mg} \mathrm{m}^{-2} \mathrm{day}^{-1} \times 3\right)$ given 4 weeks before carboplatin. Patients treated on the PNET study received both cyclophosphamide $\left(2 \mathrm{gm}^{-2}\right.$ day $\left.{ }^{-1} \times 2\right)$ and thiotepa $\left(300 \mathrm{mg} \mathrm{m}^{-2} \mathrm{day}^{-1}\right)$ before high-dose carboplatin with time between chemotherapy treatments dependent on neutrophil and platelet count recovery.

specific tumour types. Toxicity following carboplatin treatment was assessed by the National Cancer Institute Common Toxicity Criteria (CTC), version 2.0.

\section{Blood sampling and analysis}

Blood samples $(2 \mathrm{ml})$ for pharmacokinetic analysis were obtained from a central line before carboplatin infusion, $30 \mathrm{~min}$ after the start of infusion, at $60 \mathrm{~min}$ (end of infusion) and at $120 \mathrm{~min}$ after the start of infusion ( $60 \mathrm{~min}$ post-infusion). All samples were taken from a different lumen from that used for drug administration. Plasma was separated from whole blood samples by centrifugation $\left(1200 \mathrm{~g}, 4^{\circ} \mathrm{C}, 10 \mathrm{~min}\right)$, and $1 \mathrm{ml}$ was then removed and placed in an Amicon Centrifree micropartition unit with a $30000 \mathrm{MW}$ cutoff (Millipore, Edinburgh, UK). This plasma sample was centrifuged $\left(1500 \mathrm{~g}, 4^{\circ} \mathrm{C}, 15 \mathrm{~min}\right)$ to obtain plasma ultrafiltrate for determination of free carboplatin levels. Samples were sent by overnight courier, on dry ice and in an insulated container, to the Northern Institute for Cancer Research, Newcastle University, and were stored at $-20^{\circ} \mathrm{C}$ before analysis.

Platinum pharmacokinetic analyses were carried out by flameless atomic absorption spectrophotometry (AAS) using a PerkinElmer AAnalyst 600 graphite furnace spectrometer (Perkin-Elmer Ltd, Beaconsfield, UK). Free or unbound platinum levels were determined in plasma ultrafiltrates as described previously (Veal et al, 2001). All samples were analysed in duplicate and values are expressed as the average of these measurements. Duplicate values were within $15 \%$ of each other in all cases. Intra- and interassay coefficients of variation for a quality assurance sample had to be $<10 \%$ for an assay to be valid. The limit of detection for the AAS assay was $0.10 \mu \mathrm{g} \mathrm{ml}^{-1}$.

\section{Pharmacokinetics and dose adjustment}

Carboplatin clearance and AUC were determined by Bayesian analysis following each dose of carboplatin using a two compart- 
ment model as described previously (Peng et al, 1995). For patients being treated on a 5-day carboplatin schedule, dosing was adjusted on days 2-5, based on drug exposures and clearance values determined for day 1 , or for days 1 and 2, to achieve the desired target cumulative AUC of $20 \mathrm{mg} \mathrm{m}^{-1}$.min. For patients being treated on the 3-day carboplatin schedule, dosing was adjusted on day 3 , based on drug exposure on day 1 , to achieve the desired target cumulative AUC of $21 \mathrm{mg} \mathrm{ml}^{-1}$.min. Carboplatin dose adjustments were recommended for all patients with day 1 AUC values $\geqslant 10 \%$ outside the target daily AUC defined in the clinical protocol on which the patient was being treated. Dose adjustments were calculated based on the actual carboplatin clearance determined on day 1 and the remaining AUC to be achieved.

\section{Platinum-DNA adduct measurement}

Whole blood samples were taken before the start of treatment, $24 \mathrm{~h}$ after the first dose of carboplatin on day 1 and $24 \mathrm{~h}$ after the final dose of carboplatin on day 5 for those patients being treated over a 5-day period. Cellular DNA was isolated from peripheral blood leucocytes as described previously (Peng et al, 1995) and the concentration of DNA in each sample was quantified by UV absorption $\left(A_{260}\right)$. DNA samples were diluted in $3.5 \%$ nitric acid and were hydrolysed overnight at $70^{\circ} \mathrm{C}$. Platinum-DNA adduct levels were determined by ultrasensitive multi-collector inductively coupled plasma mass spectrometry (ICP-MS) as described previously (Cooper et al, 2004; Nowell et al, 2005). The limits of detection and quantitation using this methodology were 0.3 and 1 amol platinum ml $\mathrm{m}^{-1}\left(1 \mathrm{amol}=1 \times 10^{-18} \mathrm{~mol} \mathrm{ml}^{-1}\right)$, respectively. Final platinum-DNA adduct levels were calculated as nmoles $\mathrm{g}^{-1}$ DNA and the results of duplicate analyses were within $10 \%$ of each other in all cases.

\section{Statistical analysis}

Linear regression analysis and the Pearson correlation coefficient were used to indicate correlations between patient GFR and \% target carboplatin AUC and between observed carboplatin AUC and platinum-DNA adduct levels. The unpaired two-sided Student's $t$-test was used to determine differences between GFR values in patients who would have experienced AUC values greater than $25 \%$ above the target AUC and in patients who would have experienced AUC values greater than $25 \%$ below the target AUC, if no carboplatin dose modification had been carried out. The paired Student's $t$-test was used to determine differences between carboplatin clearance values observed on day 1 vs day 3 and on day 1 vs day 5 of treatment. Log-transformed values of AUC, GFR and clearance were used for all statistical tests described.

\section{RESULTS}

\section{Patient characteristics and treatment}

Children were treated at 12 UKCCSG centres for soft tissue sarcoma or recurrent primitive neuroectodermal tumour. Twentyeight children and adolescents receiving carboplatin were entered onto the two studies between September 1998 and November 2005. The study population had a mean age of 11.7 years (range $1-21$ ) and included 14 men and 14 women. Renal function-based carboplatin dosing was carried out on day 1 of treatment, with the target exposure defined in the clinical protocol on which the child was being treated. Patient characteristics including age, sex and tumour type are given in Table 1 .

\section{Pharmacokinetics and dose adjustment}

Carboplatin clearance values ranged from 25 to $195 \mathrm{ml} \mathrm{min}^{-1}$ and showed a good correlation with GFR values of $21-228 \mathrm{ml} \mathrm{min}^{-1}$ $\left(50-200 \mathrm{ml} \mathrm{min}^{-1} 1.73 \mathrm{~m}^{-2}\right)$ determined before day 1 of treatment $(r=0.73, P<0.0001)$. No significant changes in clearance were observed in those patients where clearance values were determined on days 1 and 3 of carboplatin treatment (mean of differences: $9.6 \mathrm{ml} \mathrm{min}^{-1} ; 95 \% \mathrm{CI}-2.9$ to $22.1 ; n=17 ; P=0.32$ ) or on days 1 and 5 of treatment (mean of differences: $8.5 \mathrm{ml} \mathrm{min}^{-1} ; 95 \% \mathrm{CI}-4.3$ to $21.3 ; n=12 ; P=0.16$ ).

Pharmacokinetic monitoring was carried out in 28 patients receiving high-dose carboplatin chemotherapy. Details of estimated and actual total doses and carboplatin exposures are shown for all patients in Table 2. On the basis of AUC values obtained on day 1 following renal function-based dosing, and target daily AUC values defined in the treatment protocol, carboplatin dose adjustment was carried out in 21 out of 28 patients (75\%). Dosage adjustments from the day 1 dose were carried out on day 2 of treatment in one patient, day 3 in 12 patients, day 4 in six patients, with two different adjustments carried out on both days 3 and 5 in the remaining two patients. Dosage adjustments in these 21 patients ranged from 7 to $67 \%$ of the initial renal function-based dose. For those patients where carboplatin dose was modified, dose increases were implemented in $43 \%$ of patients $(9 / 21)$ and dose reductions in 57\% (12/21). Examples of carboplatin dosing and exposure in individual patients requiring dosage adjustments based on drug exposure data are shown in Figure 1. Overall, pharmacokinetically guided dose adjustment resulted in achievement of AUC values of $16.7-25.2 \mathrm{mg} \mathrm{ml}^{-1}$. min (84-126\% of target AUC values) as compared to estimated AUC values of $13.0-$ $44.7 \mathrm{mg} \mathrm{ml}^{-1}$. $\mathrm{min}(65-213 \%$ of target AUC values) without dose adjustment (Figure 2). Estimated AUC values were calculated based on the observed daily carboplatin clearance values, assuming that the day 1 renal function-based dose had been administered on each day of treatment, as opposed to the adjusted dose actually administered.

The relationship between the renal function of patients receiving high-dose carboplatin treatment and the predicted AUC that would have been obtained if no dose modification had been carried out is shown in Figure $3(r=0.54 ; P=0.003)$. Pretreatment GFR values were higher in those patients who would have experienced AUC values greater than $25 \%$ above the target AUC (mean value $121 \mathrm{ml} \mathrm{min}^{-1}$, range $94-158$; standardized mean value $137 \mathrm{ml} \mathrm{min}^{-1} 1.73 \mathrm{~m}^{-2}$, range $81-200 ; n=8$ ) than those who would have experienced AUC values $>25 \%$ below the target AUC (mean value $57 \mathrm{ml} \mathrm{min}^{-1}$, range $32-101$; standardized mean value $81 \mathrm{ml} \mathrm{min}^{-1} 1.73 \mathrm{~m}^{-2}$, range $\left.50-111 ; n=5\right)(P=0.0139)$.

\section{Platinum - DNA adduct measurements}

Carboplatin-DNA adduct levels were measured in DNA samples isolated from peripheral blood leucocytes from 8 of the 17 patients on the MMT 98 study on a total of 12 courses of carboplatin administration. Samples were obtained following carboplatin dosed to a target AUC of $4 \mathrm{mg} \mathrm{ml}^{-1} \cdot \mathrm{min}$ on day 1 of a 5-day course of treatment in six patients (carboplatin dose range: $380-$ $957 \mathrm{mg}$ ), following carboplatin on day 5 of treatment in four of these patients (carboplatin dose range: $203-860 \mathrm{mg}$ ) and following a single dose of carboplatin targeted to an AUC of $10 \mathrm{mg} \mathrm{ml}^{-1}$.min as part of a phase II window study in a total of three patients (carboplatin dose range: $1140-1550 \mathrm{mg}$ ). Platinum-DNA adduct levels determined $24 \mathrm{~h}$ post-administration on day 1 of treatment ranged from 0.24 to 2.29 nmoles $^{-1}$ DNA and correlated with the observed carboplatin AUC values as shown in Figure $4(r=0.84$, $P=0.0006$ for all data points shown; $r=0.81, P=0.01$ when the analysis is limited to a single data point for each individual patient). Additional measurements determined $24 \mathrm{~h}$ post-administration on day 5 of treatment were obtained for four patients and indicated a clear increase in platinum-DNA adduct levels as compared to the corresponding day 1 levels $(P=0.01)$, suggesting an increased level of adduct formation or an accumulation of 
Table 2 Carboplatin doses and estimated renal function-based dosing AUC vs actual AUC following pharmacologically guided dosing

\begin{tabular}{|c|c|c|c|c|c|c|c|c|c|c|}
\hline \multirow[b]{2}{*}{ Study } & \multirow[b]{2}{*}{ Patient } & \multirow[b]{2}{*}{ 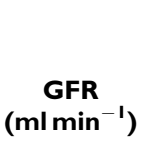 } & \multirow[b]{2}{*}{$\begin{array}{l}\text { Target AUC } \\
\left(\mathrm{mg} \mathrm{ml} \mathbf{~ m i n}^{-1} \cdot \mathrm{min}\right)\end{array}$} & \multirow[b]{2}{*}{$\begin{array}{c}\text { Dose } \\
\text { modification }\end{array}$} & \multirow[b]{2}{*}{$\begin{array}{l}\text { Estimated total } \\
\text { dose }(\mathrm{mg})^{\mathrm{a}}\end{array}$} & \multirow[b]{2}{*}{$\begin{array}{l}\text { Actual total } \\
\text { dose }(\mathrm{mg})\end{array}$} & \multicolumn{2}{|c|}{ Estimated } & \multicolumn{2}{|c|}{ Achieved } \\
\hline & & & & & & & $\begin{array}{c}\text { AUC }^{b} \\
\left(\mathrm{mg} \mathrm{ml}^{-1} \cdot \mathrm{min}\right)\end{array}$ & $\begin{array}{c}\% \text { target } \\
\text { AUC }\end{array}$ & $\begin{array}{c}\text { AUC } \\
\left(\mathrm{mg} \mathrm{ml}^{-1} \cdot \mathrm{min}\right)\end{array}$ & $\begin{array}{c}\% \text { Target } \\
\text { AUC }\end{array}$ \\
\hline \multirow[t]{17}{*}{ MMT 98} & 1 & 110 & 20 & Day 3 & 2610 & 1653 & 30.3 & 152 & 19.6 & 98 \\
\hline & 2 & 115 & 20 & Day 3 & 2720 & 2921 & 18.7 & 94 & ND & ND \\
\hline & 3 & 104 & 20 & Day 3 & 2350 & 1450 & 32.0 & 160 & 19.8 & 99 \\
\hline & 4 & 158 & 20 & Day 2 & 3660 & 2868 & 32.6 & 163 & 25.2 & 126 \\
\hline & 5 & 85 & 20 & None & 2090 & 2090 & 20.7 & 104 & 20.7 & 104 \\
\hline & 6 & 71 & 20 & None & 1750 & 1750 & 21.5 & 108 & ND & ND \\
\hline & 7 & 73 & 20 & Day 4 & 1900 & 2860 & 15.4 & 77 & 23.7 & 119 \\
\hline & 8 & 90 & 20 & Day 4 & 1565 & 1243 & 23.8 & 119 & 19.0 & 95 \\
\hline & 9 & 21 & 20 & Day 3 & 575 & 508 & 22.5 & 113 & ND & ND \\
\hline & 10 & 228 & 20 & Day 3 & 4785 & 4071 & 23.5 & 118 & ND & ND \\
\hline & || & 30 & 20 & Day 3 & 750 & 970 & 16.9 & 85 & 22.1 & $11 \mid$ \\
\hline & 12 & 56 & 20 & Days $3 / 5$ & 1350 & 1790 & 14.8 & 74 & 19.3 & 97 \\
\hline & 13 & 59 & 20 & Days $3 / 5$ & 1475 & 1575 & 17.9 & 90 & 19.5 & 98 \\
\hline & 14 & 62 & 20 & Day 4 & 1500 & 2500 & 13.0 & 65 & 22.6 & 113 \\
\hline & 15 & 97 & 20 & Day 4 & 2160 & 2696 & 15.0 & 75 & 18.8 & 94 \\
\hline & 16 & 101 & 20 & Day 4 & 2650 & 4070 & 13.0 & 65 & ND & ND \\
\hline & 17 & 145 & 20 & Day 4 & 3400 & 2664 & 26.5 & 133 & 20.1 & $10 \mid$ \\
\hline \multirow[t]{13}{*}{ PNET } & 18 & 34 & 21 & None & 1026 & 1026 & 15.3 & 73 & ND & ND \\
\hline & 19 & 104 & 21 & Day 3 & 3720 & 2830 & 27.6 & $13 \mid$ & ND & ND \\
\hline & 20 & 74 & 21 & None & 1590 & 1590 & 16.7 & 80 & 16.7 & 80 \\
\hline & 21 & 97 & 21 & Day 3 & $314 \mid$ & 2554 & 25.8 & 123 & ND & ND \\
\hline & 22 & 124 & 21 & Day 3 & 3258 & 2387 & 30.7 & 146 & 20.7 & 99 \\
\hline & 23 & 32 & 21 & Day 3 & 900 & 1130 & 14.5 & 69 & 19.0 & 90 \\
\hline & 24 & 128 & 21 & Day 3 & 4320 & 2880 & 44.7 & 213 & ND & ND \\
\hline & 25 & 74 & 21 & None & 1608 & 1608 & 21.0 & 100 & 21.0 & 100 \\
\hline & 26 & 42 & 21 & None & 1020 & 1020 & 20.1 & 96 & 20.1 & 96 \\
\hline & 27 & 94 & 21 & Day 3 & 3000 & 2360 & 26.7 & 127 & ND & ND \\
\hline & 28 & 40 & 21 & None & 870 & 870 & 20.2 & 96 & 20.2 & 96 \\
\hline & & & & & Range: & MMT 98 & $13.0-32.6$ & $65-163$ & $18.8-25.2$ & $94-126$ \\
\hline & & & & & & PNET & $14.5-44.7$ & $69-213$ & $16.7-21.0$ & $80-100$ \\
\hline
\end{tabular}

${ }^{a}$ Estimated total dose is based on the day I renal function-based dose without modification. ${ }^{b}$ Estimated total AUC is that which would have resulted if no dose adjustment had been made (based on daily carboplatin clearance values)

adducts over the 5-day treatment period (Table 3). Overall, platinum-DNA adduct levels ranged from 0.24 to 6.99 nmole g $^{-1}$ DNA, with corresponding peak unbound carboplatin plasma concentrations ranging from 15.8 to $76.6 \mu \mathrm{g} \mathrm{ml}^{-1}$. These levels are well above the limits of detection and quantitation of the ICPMS technique used (16). No correlations were observed between platinum-DNA adduct formation and other parameters investigated, such as body weight, age or gender of patients studied.

\section{Carboplatin toxicity}

Toxicity data were available for a total of 23 of the 28 patients studied, including 14 patients treated on the MMT 98 study and nine patients on the PNET study. Haematological toxicity (CTC grade 3 or 4), including neutropenia and thrombocytopenia, was observed in $91 \%(21 / 23)$ of patients overall. This level of haematological toxicity was reported in $86 \%$ of MMT 98 patients $(12 / 14)$, who received carboplatin targeted to an AUC of $20 \mathrm{mg} \mathrm{ml}^{-1}$.min over a 5-day treatment period, and in $100 \%$ of patients (9/9), who received high-dose carboplatin targeted to an AUC of $21 \mathrm{mg} \mathrm{ml}^{-1}$.min over the shorter 3 day regimen on the PNET study. No treatment-related deaths were observed in any of the 28 patients studied.

\section{DISCUSSION}

The current study was carried out to investigate the variation in carboplatin pharmacokinetics and exposure and to determine the potential importance of therapeutic monitoring following highdose carboplatin treatment in children. In addition, platinumDNA adduct levels were measured in peripheral blood leucocytes, to allow a comparison of carboplatin pharmacodynamics and pharmacokinetics alongside clinical toxicity data. Clinical response data were not evaluated due to the potential role played by concomitant chemotherapy, administered either before or following high-dose carboplatin treatment, on the tumour responses observed.

A total of 28 patients were included in the study with the dose of carboplatin on day 1 based on renal function to achieve a target AUC. No significant interoccasion variability in carboplatin clearance was observed in those patients where clearance values were determined on the first and last days of treatment, although mean clearance values were lower on days 3 and $5 v s$ comparable day 1 data. Interestingly, these data are in agreement with those published from a phase I study, which reported a statistically significant, but limited, decrease in clearance between days 1 and 5 of high-dose carboplatin treatment (Rubie et al, 2003).

On the basis of the observed AUC values in individual patients, carboplatin dose adjustment was carried out in $75 \%$ of patients, with a range of dose adjustments up to a maximum of $67 \%$ from the initial estimated dose. These dose changes resulted in drug exposures of $84-126 \%$ of the target AUC values as defined in the two study protocols. In comparison, estimated carboplatin exposures of $65-213 \%$ of the target AUC values would have been attained without dose adjustment, with $32 \%$ of patients (9/28) receiving carboplatin AUC values above $25 \mathrm{mg} \mathrm{ml}^{-1}$.min. The likelihood of dose adjustment was not influenced by the method of 

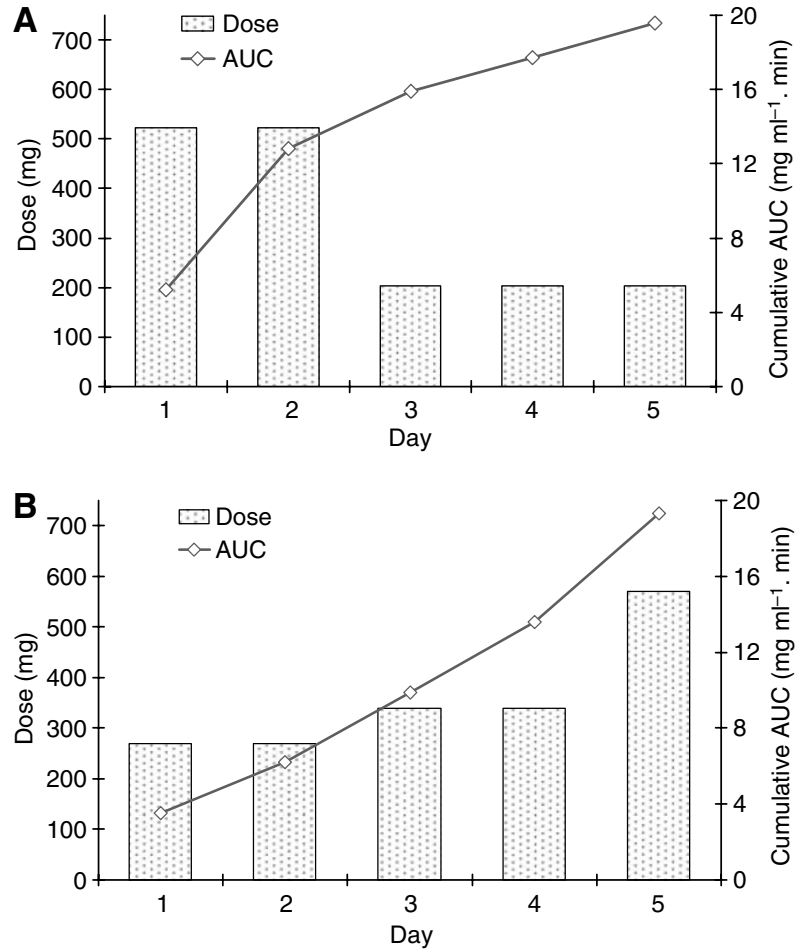

Figure I Examples of carboplatin pharmacokinetically guided dosing and exposure $(A \cup C)$ in individual patients showing $(\mathbf{A})$ a dose reduction implemented on day 3 to achieve a cumulative $A \cup C$ of $19.6 \mu \mathrm{g} \mathrm{ml}^{-1}$.min over 5 days of treatment and (B) dose increases on days 3 and 5 resulting in a cumulative AUC of $19.3 \mu \mathrm{g} \mathrm{ml}^{-1}$.min.

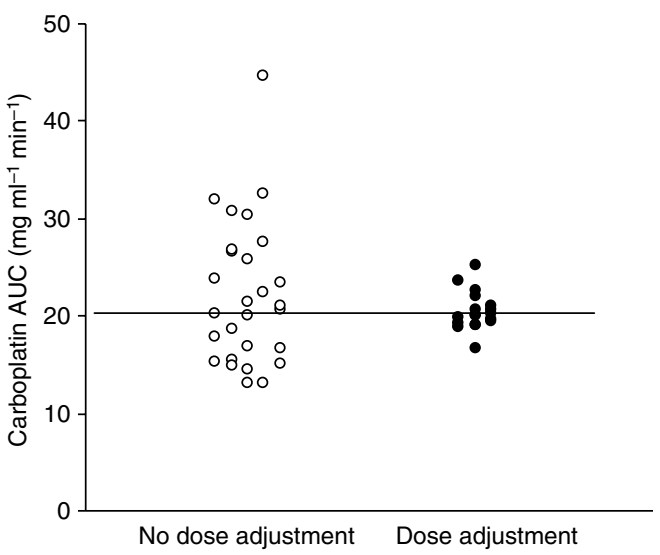

Figure 2 Predicted vs actual carboplatin exposures following pharmacokinetically guided dosage adjustment in children receiving high-dose carboplatin chemotherapy $(n=28)$.

GFR determination or the dosing equation used to determine initial renal function-based dosing. Based on previous studies showing correlations between carboplatin AUC and drug toxicity following high-dose chemotherapy, it is likely that patients with an AUC greater than $25 \mathrm{mg} \mathrm{ml}^{-1}$.min would have experienced serious side effects if therapeutic monitoring had not been implemented (Huitema et al, 2002; Kloft et al, 2002). Indeed, significantly increased frequencies of nephrotoxicity, ototoxicity and peripheral

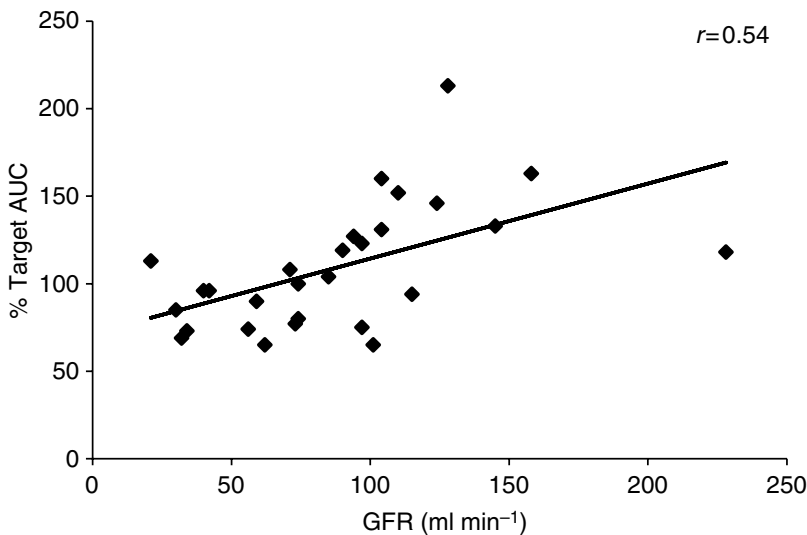

Figure 3 Correlation between patient renal function (GFR) and estimated \% target carboplatin AUC with no pharmacological dose adjustment $(n=28)$.

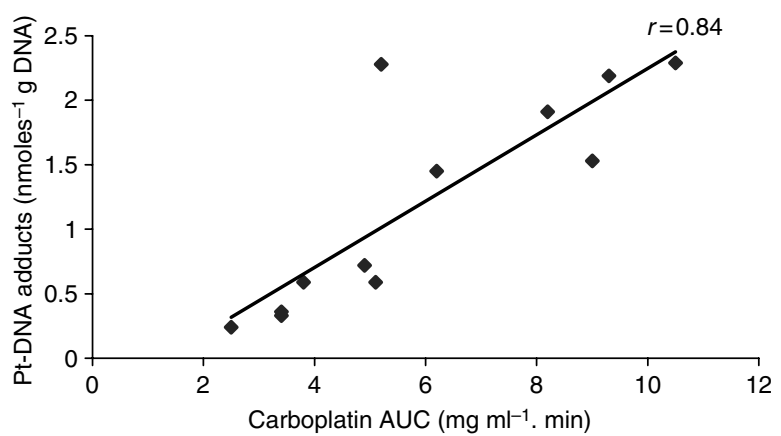

Figure 4 Correlation between actual carboplatin exposure (AUC) and platinum-DNA adduct levels measured in peripheral blood leucocytes obtained $24 \mathrm{~h}$ after high-dose carboplatin administration on day I of a course of treatment. Data represents samples analysed from six patients receiving carboplatin on day I of high-dose carboplatin treatment (MMT 98 study) and three patients receiving carboplatin on day I of each of two courses of a high-dose carboplatin window study (MMT 98).

Table 3 Platinum-DNA adduct levels determined in patients following carboplatin administration on days I and 5 of treatment in four patients on the MMT 98 protocol

\begin{tabular}{|c|c|c|c|c|}
\hline Patient & $\begin{array}{l}\text { Study } \\
\text { day }\end{array}$ & $\begin{array}{l}\text { Carboplatin } \\
\text { dose }(\mathbf{m g})\end{array}$ & $\begin{array}{c}\text { Carboplatin AUC } \\
\left(\mathrm{mg} \mathrm{ml}^{-1} \cdot \mathrm{min}\right)\end{array}$ & $\begin{array}{l}\text { Pt-DNA adducts } \\
\text { (nmol g }{ }^{-1} \text { DNA) }\end{array}$ \\
\hline \multirow[t]{2}{*}{1} & 1 & 522 & 5.2 & 2.28 \\
\hline & 5 & 203 & 1.9 & 6.99 \\
\hline \multirow[t]{2}{*}{2} & I & 380 & 2.5 & 0.24 \\
\hline & 5 & 860 & 7.8 & 2.21 \\
\hline \multirow[t]{2}{*}{3} & 1 & 732 & 5.1 & 0.59 \\
\hline & 5 & 534 & 5.8 & 4.06 \\
\hline \multirow[t]{2}{*}{4} & 1 & 418 & 3.8 & 0.57 \\
\hline & 5 & 418 & 4.2 & 3.21 \\
\hline
\end{tabular}

nervous system toxicities were observed in patients with AUC above $24.2 \mathrm{mg} \mathrm{ml}^{-1}$. min in a recently published study in patients with germ-cell cancer (Kloft et al, 2003).

In the current study, a positive correlation was observed between renal function (GFR) and the estimated AUC that would have been observed if pharmacologically guided dosing had not been performed. Pretreatment GFR values were significantly higher in those patients whose AUC values would have exceeded 
the target by $25 \%$ without dose modification $(n=8)$, than in those whose AUC values would have been more than 25\% below the target AUC $(n=5)$. There was a greater than twofold difference in mean GFR between these two groups $(P=0.0139)$. These data suggest that the current use of dosing equations is less effective when dealing with patients receiving high-dose carboplatin chemotherapy, with children with higher GFR values being more likely to attain AUC values greater than intended, and those with lower GFR values being at a greater risk of under-exposure.

Platinum-DNA adducts were measured at $24 \mathrm{~h}$ after carboplatin administration, as this has previously been shown to be the time when peak adduct levels are observed following platinum drug treatment (Peng et al, 1997). In addition, this allowed the blood sample to be drawn immediately before the next dose of carboplatin being administered in those patients receiving the drug over several days. A strong correlation was observed between the formation of platinum - DNA adducts and carboplatin AUC on day 1 of treatment, with higher adduct levels being observed in peripheral blood leucocytes obtained from patients with higher plasma carboplatin concentrations. Pharmacokinetic-pharmacodynamic comparisons with the platinum drugs have not always shown a consistent positive relationship (Schellens et al, 1996; Peng et al, 1997; Veal et al, 2001). However, carboplatin seems to show a stronger trend towards such a relationship than does cisplatin (Ghazal-Aswad et al, 1999). The correlation between this pharmacodynamic measure and drug exposure supports the use of dosing based on renal function and adaptive dosing to achieve target carboplatin AUC values. Similarly, the lack of a pharmacokinetic-pharmacodynamic relationship for cisplatin may explain why such an approach to dosing has not been established for this drug.

The current study also suggests that when carboplatin is administered over several days, there is either an increased formation of platinum-DNA adducts or an accumulation of adducts over the treatment period. Despite the complication of carboplatin dose variations between days 1 and 5 of treatment, owing to pharmacokinetic dose adjustment, adduct levels following carboplatin administration on day 5 were between 3- and 10 -fold higher than the corresponding levels following day 1 of the treatment. This phenomenon may explain some of the apparent inconsistencies in published pharmacokinetic-pharmacodynamic relationships for this drug. For example, although a strong correlation was observed between platinum-DNA adduct levels and carboplatin systemic exposure following administration on day 1 in the current study, the accumulation of adduct levels observed following several days of treatment negated this relationship when data from all days of treatment were included in a similar analysis. Although we are unable to determine cumulative platinum-DNA adduct levels over the 5-day treatment period, with no information on adduct levels on days $2-4$, it is possible that differences in total adduct levels may reflect differences in observed toxicity among some patients, despite comparable cumulative pharmacokinetic exposures in terms of AUC. Indeed, correlations have previously been shown between platinum-DNA adduct levels and leukocytopenia following cisplatin treatment (Veal et al, 2001).

Haematological toxicity was observed in the vast majority of patients studied (90\%), as anticipated with the use of high-dose carboplatin chemotherapy. The high percentage of patients experiencing CTC grade 3 and 4 haematological toxicity is likely to be associated with the high carboplatin exposures achieved in all patients through adaptive dosing. Estimated exposures as low as $13.0 \mathrm{mg} \mathrm{ml}^{-1}$.min, which would have been achieved in some of the patients studied if dose adjustment had not been carried out, may not have led to the same grade toxicity but may also have been less likely to have resulted in clinical responses. Correlations between decreased carboplatin AUC values and increased rates of relapse have previously been reported in patients with testicular germ-cell tumours (Horwich et al, 1991). Although an evaluation of clinical response data was not included in this study, owing to the potential influence of concomitant chemotherapy, it is encouraging that no treatment-related deaths were observed in any of the patients on the current study. This is particularly the case in light of the high incidence of treatment-related deaths previously reported with the use of high-dose carboplatin in paediatric patients (Santana et al, 1992; Jakacki et al, 1997; Dunkel et al, 1998).

Data from this multi-centre study show the feasibility of real-time monitoring of carboplatin pharmacokinetics with adaptive dosing and indicate that this approach is necessary for the attainment of consistent AUC values in individual patients receiving high-dose carboplatin treatment. This approach is now being used in clinical studies in the UK, with the aim of improving efficacy and minimising toxicity of carboplatin in similar high-dose protocols, and is likely to be relevant to the treatment of both childhood and adult cancer patients. The pharmacodynamic data presented here suggest that a strong correlation exists between the pharmacokinetics of carboplatin and the drug-target interaction.

\section{ACKNOWLEDGEMENTS}

We thank the patients, research nurses and clinicians who participated in the study at the following UKCCSG centres: Royal Victoria Infirmary, Newcastle upon Tyne; Great Ormond Street Hospital, London; Manchester Children's Hospital; St. James's Hospital, Leeds; Royal Liverpool Children's Hospital; Royal Marsden Hospital, Surrey; Addenbrooke's Hospital, Cambridge; Bristol Royal Hospital for Children, Bristol; Southampton General Hospital; Birmingham Children's Hospital; Children's Hospital for Wales, Cardiff. This study was supported by a grant from Cancer Research UK.

\section{REFERENCES}

Ando M, Minami H, Ando Y, Saka H, Sakai S, Yamamoto M, Sasaki Y, Shimokata K, Hasegawa Y (2000) Multi-institutional validation study of carboplatin dosing formula using adjusted serum creatinine level. Clin Cancer Res 6: $4733-4738$

Calvert AH, Newell DR, Gumbrell LA, O'Reilly S, Burnell M, Boxall FE, Siddik ZH, Judson IR, Gore ME (1989) Carboplatin dosage: prospective evaluation of a simple formula based on renal function. J Clin Oncol 7: $1748-1756$

Chatelut E, Pivot X, Otto J, Chevreau C, Thyss A, Renee N, Milano G, Canal P (2000) A limited sampling strategy for determining carboplatin AUC and monitoring drug dosage. Eur J Cancer 36: 264-269

Cooper B, Veal GJ, Radivoyevitch T, Tilby MJ, Meyerson HJ, Lazarus HM, Koc ON, Creger RJ, Pearson G, Nowell G, Gosky D, Ingalls ST, Hoppel CL, Gerson SL (2004) A Phase I and pharmacodynamic study of fludarabine, carboplatin and topotecan in patients with relapsed, refractory, or high-risk acute leukemia. Clin Cancer Res 10: 6830-6839

Dunkel IJ, Boyett JM, Yates A, Rosenblum M, Garvin Jr JH, Bostron BC Goldman S, Sender LS, Gardner SL, Li H, Allen JC, Finlay JL (1998) Highdose carboplatin, thiotepa and etoposide with autologous stem-cell rescue for patients with recurrent medulloblastoma. J Clin Oncol 16: 222-228

Gaynon PS (1994) Carboplatin in pediatric malignancies. Semin Oncol 21(Suppl 12): $65-76$ 
Ghazal-Aswad S, Tilby MJ, Lind M, Baily N, Sinha DP, Calvert AH, Newell DR (1999) Pharmacokinetically guided dose escalation of carboplatin in epithelial ovarian cancer: effect on drug-plasma AUC and peripheral blood drug-DNA adduct levels. Ann Oncol 10: 329-334

Horwich A, Dearnaley DP, Nicholls J, Jay G, Mason M, Harland S, Peckham MJ, Hendry WF (1991) Effectiveness of carboplatin, etoposide, and bleomycin combination chemotherapy in good-prognosis metastatic testicular nonseminomatous germ cell tumours. J Clin Oncol 9: 62 -69

Huitema ADR, Spaander M, Mathot RAA, Tibben MM, Holtkamp MJ, Beijnen JH, Rodenhuis S (2002) Relationship between exposure and toxicity in high-dose chemotherapy with cyclophosphamide, thiotepa and carboplatin. Ann Oncol 13: 374-384

Jakacki RI, Jamison C, Heifetz SA, Caldemeyer K, Hanna M, Sender L (1997) Feasibility of sequential high-dose chemotherapy and peripheral blood stem cell support for pediatric central nervous system malignancies. Med Pediatr Oncol 29: 553-559

Jodrell DI, Egorin MJ, Canetta RM, Langenberg P, Goldbloom EP, Burroughs JN, Goodlow JL, Tan S, Wiltshaw E (1992) Relationships between carboplatin exposure and tumor response and toxicity in patients with ovarian cancer. J Clin Oncol 10: $520-528$

Kloft C, Siegert W, Beyer J, Jaehde U (2002) Toxicity of high-dose carboplatin: ultrafiltered and not total plasma pharmacokinetics is of clinical relevance. J Clin Pharmacol 42: $762-763$

Kloft C, Siegert W, Jaehde U (2003) Individualised dosing strategy for high-dose carboplatin in patients with germ cell cancer. Br J Cancer 89: $787-794$

Newell DR, Pearson ADJ, Balmanno K, Price L, Wyllie RA, Keir M, Calvert AH, Lewis IJ, Pinkerton CR, Stevens MC (1993) Carboplatin pharmacokinetics in children: the development of a pediatric dosing formula. J Clin Oncol 11: 2314-2323

Newell DR, Siddik ZH, Gumbrell LA, Boxall FE, Gore ME, Smith IE, Calvert AH (1987) Plasma free platinum pharmacokinetics in patients treated with high dose carboplatin. Eur J Cancer Clin Oncol 23: 1399-1405

Nowell GM, Pearson DG, Ottley CJ, Tilby M (2005) Accurate determination of platinum concentrations at ultra-low levels in clinical DNA samples with high Hf/Pt ratios using the Thermo Finnigan Neptune Plasma Ionization Multi-collector Mass Spectrometer (PIMMS). In: JG, Bandura DR (eds) Plasma Source Mass Spectrometry: Current Trends and Future Developments. Royal Society of Chemistry: Holland, pp. 245-258
Peng B, Boddy AV, Cole M, Pearson AD, Chatelt E, Rubie H, Newell DR (1995) Comparison of methods for the estimation of carboplatin pharmacokinetics in paediatric cancer patients. Eur J Cancer 31A: $1804-1810$

Peng B, Tilby MJ, English MW, Price L, Pearson ADJ, Boddy AV, Newell DR (1997) Platinum-DNA adduct formation in leucocytes of children in relation to pharmacokinetics after cisplatin and carboplatin therapy. Br J Cancer 76: 1466 - 1473

Reed E, Ostchega Y, Steinberg SM, Yuspa SH, Young RC, Ozols RF, Poirier MC (1990) Evaluation of platinum - DNA adduct levels relative to known prognostic variables in a cohort of ovarian cancer patients. Cancer Res 50: $2256-2260$

Rubie H, Doz G, Vassal G, Chastagner P, Gentet JC, Urien S, Bastian G, Drouard-Troalen L, Barberi-Heyob M, Catalin J, Chatelut E (2003) Individual dosing of carboplatin based on drug monitoring in children receiving high-dose chemotherapy. Eur J Cancer 39: 1433-1438

Santana VM, Schell MJ, Williams R, Bowman LC, Thompson EI, Brenner MK, Mirro Jr J (1992) Escalating sequential high-dose carboplatin and etoposide with autologous marrow support in children with relapsed solid tumours. Bone Marrow Transplant 10: 457-462

Schellens JH, Ma J, Planting AS, van der Burg ME, van Meerten E, de BoerDennert M, Schmitz PI, Stoter G, Verweij J (1996) Relationship between the exposure to cisplatin, DNA-adduct formation in leucocytes and tumour response in patients with solid tumours. $\mathrm{Br} J$ Cancer 73: $1569-1575$

Thomas HD, Boddy AV, English MW, Hobson R, Imeson J, Lewis I, Morland B, Pearson ADJ, Pinkerton R, Price L, Stevens M, Newell DR (2000) Prospective validation of renal function-based carboplatin dosing in children with cancer: a United Kingdom Children's Cancer Study Group trial. J Clin Oncol 18: 3614-3621

Veal GJ, Boddy AV, Thomas HD, Price E, Parry A, Hale J, Pearson ADJ, Dick G, Atra A, Newell DR (1999) Real-time monitoring of carboplatin pharmacokinetics in paediatric patients receiving high dose chemotherapy. Br J Cancer 80(Suppl 2): 93 (abstract)

Veal GJ, Dias C, Price L, Parry A, Errinton J, Hale J, Pearson ADJ, Boddy AV, Newell DR, Tilby MJ (2001) Influence of cellular factors and pharmacokinetics on the formation of platinum-DNA adducts in leukocytes of children receiving cisplatin therapy. Clin Cancer Res 7: $2205-2212$ 